BLS 34, No 1 2008. DOI: http://dx.doi.org/10.3765/bls.v34i1.3582

(published by the Berkeley Linguistics Society and the Linguistic Society of America)

\title{
The Agent-Obfuscating Function of Mono 'Things' in Japanese Discourse
}

\author{
NINA AZUMI YOSHIDA \\ University of California, Los Angeles
}

\section{Introduction ${ }^{1}$}

A noted characteristic of the Japanese language is its preference for grammatical patterns that suppress or obfuscate (individual) human agency (e.g. passives, honorifics, subject-ellipsis, etc.) This tendency is claimed to be a linguistic manifestation of Japan's collectivistic behavioral and cultural norms (Ikegami 1981, Yamamoto 2006). This study examines another phenomenon in Japanese seen as reflective of this cultural concept, namely, the modal functions of mono in Modern Japanese, and presents a unitary analysis to account for the seeming multi-functionalities the morphosyntactic unit mono has as a marker of speaker modality in Japanese discourse.

The analysis is termed a unitary one in claiming that a continuity exists in the semantics born by mono in each of its different modal uses, and that these represent inferable extensions of mono's primary meaning as a nominal that arise as a result of this element's occurrence in certain constructions which have become grammaticalized (Hopper and Traugott 1993) in Modern Japanese. It will also be suggested that the obfuscation of the speaker as (an event-controllable) agent is a functional byproduct of such mono constructions in the context of discourse. In further illustration of the linguistic phenomenon under examination, the following section briefly surveys the main lexical and grammatical uses of mono in contemporary Japanese. In order to highlight the uses particular to it, mono will be compared, where relevant, against another nominal considered quite similar to it in meaning - namely, koto.

\footnotetext{
1 The following abbreviations are used: $\mathrm{ACC}=$ Accusative; $\mathrm{ALL}=\mathrm{Allative;} \mathrm{ASP}=\mathrm{Aspect}$; $\mathrm{CL}=$ Clause; $\quad \mathrm{CONJ}=$ Conjunctive; $\mathrm{COP}=$ Copula; $\mathrm{DAT}=$ Dative; $\mathrm{DES}=$ Desiderative; $\mathrm{NEG}=$ Negative; $\mathrm{NOM}=$ Nominative; $\mathrm{NPST}=$ Nonpast; POL $=$ Polite; PRX=Prefix; PST=Past; $\mathrm{QT}=$ Quotative; $\mathrm{SE}=$ Sentence Extender; $\mathrm{TE}=\mathrm{Te}$ Connective; $\mathrm{TMP}=\mathrm{Temporal}$; $\mathrm{TOP}=\mathrm{Topic}$
} 


\section{Nina Azumi Yoshida}

\section{Lexical and Grammatical Uses of Mono and Koto}

As lexical items, both mono and koto have traditionally been categorized in Japanese grammar as belonging to a relatively small and closed set of nominals called keisiki meisi ('formal nouns') and as such, are said to possess a minimal and opaque meaning, much like thing $(s)$ of English. Being formal or dependent nouns, mono as well as koto typically occurs with a modifier, but may appear alone in the limited contexts of fixed or idiomatic expressions. ${ }^{2}$

\subsection{Mono and Koto as Head Nouns}

Generally speaking, mono and koto express the meaning 'thing' of English. Reference grammars for students of Japanese commonly explain the choice between them as being governed by the opposing semantic notions of "concrete" versus "abstract" (Martin 1975, McGloin 1989), or "tangible" vs. "intangible" (Makino and Tsutsui 1986). Consider the following sentences taken from McGloin (1989), ${ }^{3}$ in which such oppositions are neatly exemplified:
a. Iroiro-na koto (*mono) o naratta. various коTO (*MONO) ACC learn:PST
'(I) learned various things.'
b. Iroiro-na mono (*koto) o katta. various MONO (*KOTO) ACC buy:PST '(I) bought various things.'

Koto is often preceded or modified by a verb phrase in the non-past or imperfect form to indicate 'the activity of'. When this koto is replaced by mono, and is preceded by a transitive verb, it indicates the object upon which the act takes place or the performer of the act. Examples of this usage are given in (2):

$$
\begin{array}{ll}
\text { Verb } & \text { Verb + koto } \\
<\text { kaku> } & <\text { kakukoto }> \\
\text { 'to write' } & \text { 'writing' }
\end{array}
$$

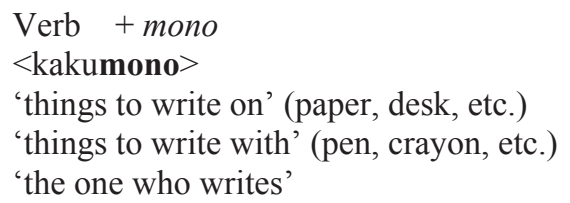
2 (i) Tosiyori wa yoku mono o sitteiru. elderly people TOP well thing ACC know:NPST
'The elderly know things well' --> 'The elderly are wise.'
(ii) Koto ga okiru mae ni syori-sita hoo ga ii. thing NOM happen:NPST before TMP deal:PST side NOM good '(It) is better (we) deal with (it) before (some)thing happens' --> '(We) should deal with (it) before an accident/incident occurs'

\footnotetext{
3 McGloin 1989: 110

${ }^{4}$ In this grammatical function, koto is more commonly recognized as a nominalizer; one of the two (along with no) existing in Modern Japanese.
} 


\section{The Agent-Obfuscating Function of Mono 'Things'}

$<$ tukuru $><$ tukurukoto $>$
'to make' 'making'
$<$ tukurumono $>$

'things to make'

'things to make (something) with'

'the one who makes'

\subsection{Prenominal/Preadjectival Uses of Mono}

Mono possesses a grammatical use whose equivalent is not found in the case of koto. When mono is attached pre-adjectivally or pre-nominally, it imparts a sense of indefiniteness or vagueness, roughly equivalent to somehow in English. It increases the ambiguity or the inability to pinpoint the underlying source of the sensation or phenomenon to which it is prefixed. Examples of this usage of mono+adjective and mono+noun are provided in (3) and (4), respectively:

sizuka / mono-sizuka
sabisii / mono-sabisii
oto ga suru /
'hear sounds'
kage ni kakureru /
'to hide in the shadows'

sizuka / mono-sizuka

'quiet; serene' / 'strangely quiet'

'lonely' / 'vaguely lonely

mono-oto ga suru

'hear the sounds of something'

mono-kage ni kakureru

'to hide in the shadows of something'

\subsection{The Mon(o)da and Kotoda Construction}

Mono (as well as koto) functions frequently as a complementizer in Japanese, the common pattern being that of mono (or koto) immediately preceded by a clause or phrase in the rentaikei 'attributive' form, and followed by the copula $d a$, as shown diagrammatically in (5):

$$
[\text { clause }]^{\text {attributive }}+\text { mono/koto }+ \text { copula } d a \text {. }
$$

The mon $(o) d a^{5}$ construction, in particular, has been identified by a number of modern Japanese grammarians (e.g. Martin 1975, Makino and Tsutsui 1986) as possessing the linguistic capacity to imbue an otherwise neutral or "objective" statement with various degrees of the speaker's subjective or emotive affect, ranging from nostalgic reminiscences, long-nurtured desires, deep amazement/ wonder, conviction toward an unquestionable/natural truth, as well as to indirect commands. Examples of each are given, respectively, in (6) to (10) below: ${ }^{6}$

$$
\begin{aligned}
& \text { Mukashi wa yoku kono kooen de asonda mon(o)da. } \\
& \text { long ago TOP well this park at play:PST MONO:COP } \\
& \text { 'Back then/Long ago, (I) sure used to play at this park a lot' }
\end{aligned}
$$

\footnotetext{
${ }^{5}$ In colloquial or informal discourse contexts, mono may take the contracted form mon; hence, monoda, may, in such contexts, become monda.

${ }^{6}$ Examples adapted from Martin (1975:725-726).
} 


\section{Nina Azumi Yoshida}

Konna rippa-na uchi ni ichido wa sumitai mon(o)da. like this magnificent house in once TOP want to live MONO:COP 'If just once, (I) sure would want to live in a magnificent house like this.'

$\begin{array}{llll}\text { Yoku(mo) anna } & \text { koto ga } & \text { ieru } & \text { mon(o)da. } \\ \text { well that kind of } & \text { thing NOM } & \text { can say:NPST } & \text { MONO:COP }\end{array}$
'It's incredible/amazing that (you) could say such a thing.'

Inu wa hoeru mon(o)da.

dog TOP bark:NPST MONO:COP

'Dogs naturally bark.'/'It's expected that dogs bark.'

Hito ni wa amari meiwaku o kakenai mon(o)da. people DAT TOP too much trouble ACC cause:NEG:NPST MONO:COP '(You) shouldn't cause people too much trouble.'

\subsection{Mono Clausal Connective Constructions}

A number of clausal linkers or clausal connective constructions that involve mono (e.g. mononara, monodakara, monode, monono, etc.) also exist in Modern Japanese. Such mono clausal connective constructions (hereafter, referred to as "mono CCCs") grammatically function to embed the mono CCC-marked clause as an adverbial and subordinate it within a main clause while semantically signaling an antecedent-consequent relationship that is either conditional (with mononara), causal (with monodakara and monode), or concessive (with monono) between the propositional contents of the two clauses they combine. An illustrative example of each of these mono CCCs are given in (11) to (14): ${ }^{7}$

Pari e ikeru mononara, itte-mitai desu.

Paris ALL can go:NPST MONO CCC go:TE-see:DES COP:POL

'If (only) (I) could go to Paris, (I) would like to go and see (how it is).'

Mada tiisakatta monodakara, yoku oboete-imasen.

still small:PST MONOCCC well remember:TE-ASP:NEG:POL

'(I) was still young, so (I) don’t remember (it) well.'

Isoide-ita monode, go-aisatu mo sezu situree simasita. hurry:TE-ASP:PST MONO CCC PFX-greeting even do:NEG be rude:PST:POL '(I) was in a hurry, so (I) was rude to not have even greeted (you).'

Kyooto made itta monono Kinkakuji wa mimasendesita.

Kyoto until go:PST MONO CCC Kinkakuji TOP see:POL:NEG:PST

'Although (I) went up to Kyoto, (I) didn't see the Kinkakuji Temple.'

In the case of examples (11)-(13), it is interesting to note that the omission of mono would still result in a grammatical sentence expressing the same conditional and causal clausal relationships.

\footnotetext{
${ }^{7}$ Examples adapted from Nagara et al. (1987:112-114).
} 


\section{The Agent-Obfuscating Function of Mono 'Things'}

\subsection{Utterance-Final Uses of Mono}

Mono (and its contracted form mon) can also appear in the utterance-final position to reflect the speaker's "stance" toward the proposition uttered. Such uses of mon (o) utterance-finally are strictly limited to casual conversation, and do not appear in written or formal spoken discourse. By adding mono, the speaker expresses a highly subjective attitude toward the proposition with the intent of "self-justification" (Fujii 2000:101), or offers an excuse or explanation based on subjective reasoning, as seen in the next question-response pair: ${ }^{8}$

(15) A: Doosite sonna-ni kaado o tukaitagaru no? why like.that credit card ACC use:DES:NPST Q 'Why do (you) (keep) want(ing) to use (your) credit card so much?'

B: Datte, genkin o tukaitakunai $n$ da but cash ACC use:DES:NEG:NPST SE COP:NPST MONO 'Cuz, (I) don't want to use cash.'

In light of its seemingly wide range of uses in Japanese grammar and discourse, previous accounts have suggested multiple functions for mono itself (e.g. as a verbal auxiliary in (6)-(10), a connective in (11)-(14), an utterance final particle in (15)). However, in taking a position similar to Fujii (2000), I will likewise maintain that it is the occurrence of mono within the context of a particular grammatical construction and discourse instance that causes it to be interpreted in association with a certain type of speaker modality. My analysis, moreover, will highlight the particular role played by mono within these constructions, notably in terms of the semantic contribution mono is making in each grammatical environment that involves it. The underlying semantics hypothesized for mono is one that has been arrived at by comparing it against koto, with which mono is claimed to stand in a mutually oppositional, semantic relationship.

\section{The Semantics of Mono}

As earlier noted, reference grammars tend to employ the conceptual terms of "concrete" or "tangible" in explaining the meaning of mono. Although such semantic notions succeed in capturing the majority of mono's lexical uses, they do not fully address the acceptability of sentences such as in (16), where the logical referent of mono does not appear to possess any obvious features of "concreteness" or "tangibility":

(16) Inoti wa tootoi mono da.

life TOP precious MONO COP

'Life is (a) precious (thing).'

\footnotetext{
${ }^{8}$ Example adapted from: http://www.enpitu.ne.jp/usr6/bin/month?id=64931\&pg=200211
} 


\section{Nina Azumi Yoshida}

Teramura (1981) has further provided the insight that mono denotes an object, or a category thereof, possessing some type of "physical concreteness" which can be perceived by one of the five bodily senses. Additionally, its meaning encompasses those phenomena having "a reality (capable of being) sensed psychologically" (Teramura 1981:754).

Taking such accounts into consideration, Yoshida (2008, to appear) has proposed a primary semantics of "physically perceived/unrationalized" for mono. Namely, mono signals an existence that is sensorily perceptible (i.e. through the five bodily senses--sight, smell, sound, taste, and touch-as well as one's inner state experiences, such as pain, hunger, emotions, etc.), and is thus indicative of a "physically perceived", and by token of this notion, an "un-rationalized" experience, an existence whose presence is "directly" perceptible, or to be perceived, without the aid or use of one's mind and its rationalizing powers. ${ }^{9}$

Furthermore, because mono's semantics denote a phenomenon whose actual existence can be validated by sensorial means alone (i.e. without the need for mental processing) it prototypically indicates a physical or material object. However, since its meaning also signals an existence whose perceived presence is to remain "unrationalized", it connotes that which "somehow exists", and by token of this, is unidentified, undifferentiated or un-individuated; namely, a "generic", "general", or "collective" entity.

In this respect, mono may potentially reference a substance having an (actual or construed) internal homogeneity, such as in the case of abstract nouns (e.g. inoti 'life', yasasisa 'kindness', kiboo 'hope'), or a person, albeit in a generic, physical sense, and would thus be inappropriate in referring to a uniquely identified individual or one meriting respect or distinction. ${ }^{10}$

Next, the structural properties of the mon $(o) d a$ construction will be discussed, along with the role which mono's proposed semantics plays within it to generate speaker modality.

\section{The Mon(o)da Construction: Structural Properties}

Yoshida (to appear) has initially proposed that the mon(o)da construction's close structural resemblance to the commentary predicate ${ }^{11}$--namely, that of a predicative clause nominalized by mono, occupying the comment position of a topic-comment (i.e. $\mathrm{NP}_{\mathrm{A}} w a \mathrm{NP}_{\mathrm{B}} d a$ ) type construction--that this is a key

\footnotetext{
9 In contrast, Yoshida (2008, to appear) proposed koto's primary semantics as "cognitively conceived/rationalized"; hence, koto refers to an existence that either has undergone or will require processing within one's mental faculties, and that one's powers of rationalization must be called in to enable this koto to become "(existentially) perceptible".

${ }^{10}$ When employed as a noun with a substantial meaning, the Japanese kanji orthography allows a distinction to be made between the mono meaning 'person' from that of 'physical object'. However, as noted above, the former refers to a person, but to one lacking distinction; hence, its common use in Japanese to humbly introduce oneself (e.g. Yosida to iu mono desu ga. / Lit. 'I am a mono (=someone) named Yoshida.')

11 This term was derived from, and is being used here with same meaning given it in Maynard (1992:591-595).
} 


\section{The Agent-Obfuscating Function of Mono 'Things'}

structural factor contributing to its pragmatic capabilities. A comparative showing of these two constructions is given below in (17):

$$
\begin{array}{cc}
<\text { TOPIC }> & <\text { C O M M N T }> \\
\text { NP }_{\text {A }} w a & \text { NP }_{\mathrm{B}} d a \\
& <M O N(\text { O) } D A> \\
& {[\text { clause }]^{\text {ATTRIB }}+\text { mono }+d a}
\end{array}
$$

It was also suggested that there exists two types of mon(o)da constructions: i) Those which may be interpreted as consisting of "regular" nominalized predicates, in that the nominal element mono serving as the head noun retains its nominal status as the referential object of the $w a$-marked topic, and ii) those which have become formulaic or grammaticalized to the extent that the mono has seemingly lost its nominal status and bears only a "non-referential" or modal meaning.

For example, in the absence of additional context, native speakers of Japanese may find the token of mon $(o) d a$ use in (18) ambiguous, with two or more possible readings as given in $(18 \mathrm{a})-(18 \mathrm{c})$ :
Hasi wa
taberu
toki ni
tukau
$\operatorname{mon}(\mathbf{0})$ da. chopsticks TOP eat:NPST when DAT use: NPST
MONO:COP
a. 'Chopsticks are (some)thing (one) uses when (one) eats.'
b. 'Normally/Generally, chopsticks are used for eating.'
c. '(You) are supposed to use (the) chopsticks for eating.'

In the first reading (18a), the head noun mono takes on a referential reading, and refers semantically to a 'thing' modified by the clause taberu toki ni tukau 'use when (one) eats', which in turn serves to comment on or define the $w a$ marked topic hasi 'chopsticks'. In the second and third, however, mono is no longer functioning as a nominal with a referent, but as a modal marker, in this case, to mark the proposition hasi wa taberu toki ni tukau 'chopsticks, (one) uses when/for eating' with the speaker's epistemic stance, as a general or commonsensical truth (in 18b), or deontic stance, as a directive (in 18c), respectively.

Thus, the predicative noun mono in the non-referential mon(o)da construction is a morphologically manifested "cue" whose function it is to direct the hearer on how, or in what manner, its nominalized propositional contents are to be received. It is this proposition, made non-challengeable ${ }^{12}$ through its nominalization, and embellished with the speaker's propositional attitude (Fujii 2000) in the form of

\footnotetext{
${ }^{12}$ As initially noted by Givon (1982), the propositional contents of a clause modifying a nominal element have been shown cross-linguistically to be 'nonchallengeable', or shielded from challenge (Givon 1982:100).
} 


\section{Nina Azumi Yoshida}

mono, which is then presented to the hearer when a non-referential type nominalized predicate like mon $(o) d a$ is uttered.

The various attitudinal stances of the speaker (e.g. deontic, epistemic, evaluative) signaled by the mon(o) $d a$ construction derive themselves from the underlying meaning mono possesses as a element in these constructions, as discussed in the section to follow.

\section{How Speaker Modality Arises in the Mon(o)da Construction}

In Yoshida (to appear), it was proposed that when mono occurs in the mon $(o) d a$ construction where it functions to convey speaker modality, thus taking on a nonreferential reading, the primary meaning signaled by this element is extended to a secondary one. Mono, whose underlying semantics denote a certain existence (i.e. one that is "physically perceived/unrationalized"), comes to connote a type of extant "truth" for an epistemic reading (as in 18b), or an "obligation" for a deontic reading (as in 18c). The speaker's choice of nominalizing a propositional content with mono functions to point out the authoritative "source" or basis behind the epistemic verity or deontic necessity so marked.

The type of authoritative source mono references derives itself by extensions both metaphorically and metonymically inferred of its proposed underlying meaning. Namely, mono, whose referential meaning as a nominal denotes an existence that occupies a vaguely defined but constant area in three-dimensional space, "shifts" by way of metaphorical extension (i.e. SPACE > TIME) to connoting a proposition with temporal persistence. Mono's semantics of denoting an "unrationalized" existence with a spatial orientation is furthermore reinterpreted as referencing a basis for a truth or obligation whose validity has persisted, unquestioned and/or unexplicated, throughout time. Moreover, a "physically-perceived" existence is metonymically (i.e. PHYSICAL > SOCIAL) reinterpreted as connoting a socially-recognized one. These mechanisms, operating synergistically, are claimed to generate such secondary meanings as "communal/social norm" or "general/consensual/common-sensical truth"13 for non-referential mono.

A definition is typically that which provides the most commonly recognized description of an entity's qualities or characteristics, namely the one most generally or normally associated with it. Thus, in the epistemic reading given in (18b), the proposition 'use when (one) eats' is being presented as a generallyknown truth regarding the wa-marked topic, 'chopsticks', and moreover, as one without need of further explication. This results in a so-called "definitional" interpretation, although strongly colored with the speaker's subjective affect that this truth is to be accepted "as is".

As initially suggested in Yoshida (2008), the deontic reading of the mon(o)da construction as an indirect command, derives as a result of pragmatic implicatures

\footnotetext{
13 This coincides with the notions of ippanteki 'generic/general' and ippansei 'generality' posited
} as the meanings of modal mono by Agetsuma (1991) and Tsubone (1994), respectively. 


\section{The Agent-Obfuscating Function of Mono 'Things'}

made on the part of the hearer when it occurs in a certain discourse context (i.e. the clause modifying mono contains a predicate with non-past inflection, typically a verb denoting an agent-controllable action, and the utterance containing this nominalized predicate is directed toward an overt or implied second-person referent).

Thus, in a situation where example (18) is directed toward a child who is using his chopsticks to play drums (instead of eating) with them, its utterance would be interpreted as a directive stating 'You're supposed to use (the) chopsticks for eating!' It is an "indirect" command in that the speaker is merely stating what the norm or desirable action should be, and it is up to the hearer to then determine how their behavior or actions (as they relate to the current discourse context) deviates from it. Through the speaker's presentation of the propositional contents as a mono, they are identifying the authoritative "voice" behind the deontic necessity as that belonging to an unindividuated (i.e. "unrationalized") aggregate of agents, namely, the society or community whom the speaker is acting as the medium for. ${ }^{14}$ This in turn, I suggest, results in an "obfuscation" or diffusion of individual agency (including that of the speaker): Precisely who or what was responsible for the establishment of this time-honored obligation/truth gets "muted" from issue. Only the actuality of the obligation/truth's existence is asserted, and this alone serves to validate its necessity or veracity.

It was aforementioned that, by token of its underlying semantics (i.e. physically-perceived/unrationalized), mono potentially references an unidentified, undifferentiated or unindividuated existence; namely, a generic, general, or collective entity possessing an internal homogeneity. Such an entity would necessarily be one lacking in agency; such individual agents would be subsumed and obfuscated within the collective whole. From this, I hypothesize that one of the major discourse functions of presenting a propositional content as a certain type of mono is to present it as one which lacks the speaker's individual agency. By extension of mono's meaning, a proposition so marked--particularly when employed to mark the speaker's own emotions or evaluative stance--is one that is "uncontrollable".

It is this secondary meaning of uncontrollability, coupled with that of temporal persistence, which gives rise to the evaluative stance mono takes on in examples (6) and (7), where it serves as the head noun of a proposition predicated by a verb in the past tense indicating a past event or action, or the desiderative (i.e. - tai form). The function of mono in such instances is to give the effect of emotional and temporal "depth" to the proposition so marked, resulting in the nostalgic recollections and long-nurtured desire readings, respectively. An

\footnotetext{
${ }^{14}$ As also claimed in Yoshida (2008) the speaker's ability to cite this social norm, in turn, serves to mark them as standing in a position of higher authority than the hearer, namely, someone who has the authority to acknowledge or identify what constitutes the norm in the community or society they are representing. Thus, by implication, this individual must necessarily be someone of greater superiority in age or experience than the hearer.
} 
Nina Azumi Yoshida

unrationalized sensation is also one that escapes one's mental grasp or which one lacks cognitive "control" over; this is rendered as the evaluative stance of deep wonder/amazement, as in example (8).

\section{Speaker Agency and Its Obfuscation in Mono CCCs}

Structurally-speaking mono CCCs consist of a clause in the rentaikee ('attributive form'), modifying the formal noun mono as a head noun, and followed by the clausal linkers nara or (da)kara, or the connective particles de or no, which in turn occupies the position of the antecedent clause and is adverbially subordinated to its consequent, main clause. This is shown diagrammatically in (19 below):

$$
\begin{aligned}
& <\text { ADVERBIAL SUBORDINATE CLAUSE }><\text { MAIN CLAUSE }> \\
& {\left[(\text { Antecedent }) \mathrm{CL}_{1}{ }^{\text {attributive }} \text { mono }+ \text { nara/dakara/de/no }\right],\left[\text { (Consequent) } \mathrm{CL}_{2}\right]}
\end{aligned}
$$

It was just suggested that a key structural factor enabling the mon(o) $d a$ construction to invoke speaker affect stems from its formal similarity to a predicate clause nominalized by, or modifying, the head noun mono followed by the copula $d a$ occupying the comment position of a topic-comment sentence, as illustrated in (16). Etymologically speaking, the conditional nara is itself an inflected form of the copula nari of Classical Japanese, while the copula da must be inserted between mono and the clause linker kara, which lends support to the notion that mono is functioning syntactically as a head noun in these two contexts. Likewise, in the case of the particles de and no, it may be pointed out that $d e$ is also the infinitive form of the copula $d a$; whereas no is the attributive form that the copula $d a$ takes to mark a noun serving as a modifier. Thus, in formal terms, mono CCCs represent instances of a clause headed by the nominal mono occupying the antecedent position of a bi-clausal construction, and thus, share the same structural patterning as the mon(o)da construction.

It was earlier noted that, in the case of examples (11)-(13), omitting the element mono still result in a well-formed sentence expressing the same conditional and causal clausal relationships. However, the addition of mono to the conditional clause in (11) reveals the speaker's attitude toward the proposition that they regard the prospects of being able to go to Paris as unlikely or even impossible. Likewise, when mono $(d a)$ is inserted before causal connectives kara and $d e$ in (12) and (13), the speaker is indicating their lack of control over the situation referred to by the causal clause, mada tisakatta '(I) was still young' or isogasikatta '(I) was busy', thereby conveying to the hearer that the inability to remember was an inevitable result stemming from an uncontrollable situation which they lacked agency over.

\section{Lack of Speaker Agency in Utterance-Final Mon(o)}

It was also earlier noted that in the contexts of informal spoken discourse, mon(o) can occur in utterance-final position with the interactional functions of a pragmatic particle. By the addition of this mon $(o)$, the speaker expresses the 


\section{The Agent-Obfuscating Function of Mono 'Things'}

highly subjective attitude that the proposition so marked--typically a reasoning or excuse--should be accepted "as is", and without further challenge; hence, it has been termed indicative of a "self-justification" (Fujii 2000). It is significant to note that in this particular usage, mon $(o)$ is functioning as an independent pragmatic particle that has lost its grammatical status as a noun.

However, despite this formal reanalysis, I claim that the pragmatic effects and attitudinal stance evoked by utterance-final mon(o) represents an inferable extension of mono's semantics as a bare noun; namely, a physical entity/truth that "somehow exists" is inferred as a line of reasoning that "somehow exists", namely a subjectively based, "self-justification" reflective of the speaker's lack of control or responsibility over it.

\section{Conclusion}

The aim of this paper has been, first, to show that a continuity exists in the semantics born by the element mono in its uses of marking speaker modality (deontic, epistemic, and evaluative) within mon(o)da, mono CCC's, and utterance-final mono. Second, to point out that these represent inferable extensions of mono's primary meaning (i.e. "physicallyperceived/unrationalized") that arise by metaphorical and metonymical means when mono occurs in certain grammaticalized constructions in Japanese discourse.

It has also been hypothesized that a key feature which remains constant throughout such modal uses of mono is a lack of individual (human) agency, and that the diffusion of speaker agency--and thus, of control and responsibility-underlie the discourse intents of such constructions involving mono.

\section{References}

Agetsuma, Yuki. 1991. Zissitu meisi "mono" to keisikiteki yoohoo to no imiteki tunagari. [The Semantic Link between Substantial Noun Mono and Its Formal Uses]. Toohoku Daigaku Bungakubu Nihongogakka Ronshuu 1:2-11.

Fujii, Seiko. 2000. Incipient Decategorizaion of MONO in Japanese Discourse. In G. Andersen and T. Freitheim, eds., Pragmatic Markers and Propositional Attitude, 83-118. Amsterdam and Philadelphia: John Benjamins Publishing Company.

Givon, Talmy. 1982. Evidentiality and Epistemic Space. Studies in Language 6:23-49.

Hopper, P. and E. C. Traugott. 1993. Grammaticalization. Cambridge: Cambridge University Press.

Ikegami, Yoshihiko. 1981. "Suru” to "Naru" no Gengogaku: Kotoba to Bunka no Taiporozii e no Siron [The Linguistics of Doing and Becoming: A Hypothesis on the Typology of Language and Culture]. Tokyo: Taisyuukan Syoten. 
Nina Azumi Yoshida

Makino, S. \& M. Tsutsui. 1986. A Dictionary of Basic Japanese Grammar. Tokyo: The Japan Times.

Martin, Samuel. 1975. A Reference Grammar of Japanese. London: Yale University Press.

Maynard, Senko K. 1992. Cognitive and Pragmatic Messages of a Syntactic Choice: The Case of the Japanese Commentary Predicate N(o)da. Text 12(4):563-613.

McGloin, Naomi. H. 1989. A Student's Guide to Japanese Grammar. Tokyo: Taisyuukan Publishing Company.

Nagara S., Hirota, N. and Nakanishi, Y. 1987. Japanese for Foreigners: Innovative Workbook in Japanese: Volume 2. Tokyo: Aratake.

Teramura, Hideo. 1981. Mono to koto [Mono and koto]. Mabuti Kazuohakase Taikankinen Kokugogaku Ronsyuu, 743-762.

Tsubone, Yukari. 1994. 'Monoda' ni kansuru ichi koosatsu [A study of monoda] Nihongo Kyooiku 84:65-77.

Yamamoto, Mutsumi. 2006. Agency and Impersonality: Their Linguistic and Cultural Manifestations. Amsterdam and Philadelphia: John Benjamins Publishing Company

Yoshida, Nina Azumi. 2008. Nominalized Predicates as Directives in Japanese Discourse. In M. E. Hudson, S. Jun, P. Sells, P. M. Clancy, S. Iwasaki and S. Sohn, eds., Japanese Korean Linguistics 13, 371-382. Stanford: CSLI Publications.

Yoshida, Nina Azumi. To appear. How 'Things' (Mono) Get Reanalyzed in Japanese Discourse. Japanese Korean Linguistics 16. Stanford: Center for the Study of Language and Information.

Nina Azumi Yoshida

University of California, Los Angeles

Department of Asian Languages and Cultures

290 Royce Hall

Los Angeles CA 90095-1540

nyoshida@ucla.edu 